\title{
Reuna
}

\section{INSTITUCIONALIZAÇÃO DE PRÁTICAS DE SUSTENTABILIDADE}

\section{INSTITUTIONALIZATION OF SUSTAINABILITY PRACTICES}

\author{
http://dx.doi.org/10.21714/2179-8834/2019v24n2p67-88
}

\author{
Cesar Mauricio Kulak \\ Universidade Estadual do Centro-Oeste (UNICENTRO), Brasil. \\ E-mail: cesarkulak@yahoo.com.br \\ Silvio Roberto Stefano \\ Universidade Estadual do Centro-Oeste (UNICENTRO), Brasil. \\ E-mail: professor-silvio@hotmail.com \\ Marcos Roberto Kuhl \\ Universidade Estadual do Centro-Oeste (UNICENTRO), Brasil. \\ E-mail: marcosrobertokuhl@yahoo.com.br
}

Submissão: 12 Jun. 2017 Publicação: 15 Out. 2019. Sistema de avaliação: Double blind review.
Centro Universitário UNA, Belo Horizonte - MG, Brasil. Editor geral: Prof. Dr. Gustavo Quiroga Souki

Este artigo encontra-se disponível nos seguintes endereços eletrônicos:

http://revistas.una.br/index.php/reuna/article/view/942

http://dx.doi.org/10.21714/2179-8834/2019v24n2p67-88

\section{Resumo}

Esta pesquisa teve como objetivo principal identificar os níveis das práticas de sustentabilidade e sua institucionalização, tendo como objetivo uma Indústria de embalagens de médio porte do interior do Paraná. Trata-se de uma pesquisa de natureza quantitativa, com coleta de dados por meio de questionário estruturado, com mensuração das questões por meio de escala intervalar do tipo likert de 5 pontos. A amostra é composta 244 questionários válidos obtidos de forma não probabilística $\mathrm{e}$ por conveniência. As análises focaram na estatística descritiva (médias e desvio padrão), na verificação da consistência interna dos construtos (alfa de Cronbach) e na verificação da existência de diferenças entre as médias (Teste t e ANOVA). Os resultados apontaram que a dimensão econômica é a mais perceptível pelos colaboradores, e deve ser trabalhado de forma conjunta com as demais dimensões. No processo de institucionalização as menores médias foram na fase de sedimentação. Pode-se inferir que as práticas ainda não estão consolidadas na organização de modo a atingir todos os seus colaboradores. Dessa maneira, entendese que a organização encontra-se no processo de habitualização e na fase de présustentabilidade, uma vez que ela exerce algumas práticas de forma isolada, sem interligação entre as dimensões da sustentabilidade. Características individuais, como sexo, escolaridade e tempo de atuação na empresa não afetam significativamente as médias.

Palavras-chave: Sustentabilidade, Práticas Sustentáveis, Institucionalização. 


\section{ABSTRACT}

The main objective of this research was to identify the levels of sustainability practices and their institutionalization, aiming at a medium-sized packaging industry in the interior of Paraná. It is a quantitative research, with data collection through a structured questionnaire, with measurement of the questions by means of an interval scale of the Likert type of 5 points. The sample is composed of 244 valid questionnaires obtained in a non-probabilistic way and for convenience. The analyzes focused on the descriptive statistics (means and standard deviation), on the internal consistency of the constructs (Cronbach's alpha) and on the verification of the existence of differences between the means (Test $t$ and ANOVA). The results pointed out that the economic dimension is the most perceptible by the employees, and must be worked together with the other dimensions. In the process of institutionalization the lower averages were in the sedimentation phase. It can be inferred that practices are not yet consolidated in the organization in order to reach all its employees. In this way, it is understood that the organization is in the process of habitualization and in the pre-sustainability phase, since it exercises some practices in isolation, without interconnection between the dimensions of sustainability. Individual characteristics, such as gender, schooling and length of time in the company do not significantly affect averages.

Keywords: Sustainability, Sustainable Practices, Institutionalization.

\section{Introdução}

Sustentabilidade é um tema que vem ganhando cada vez mais espaço e relevância dentro da sociedade, em especial nas organizações. Muitas empresas, inclusive, já adotam estratégias e a elaboração de relatórios de sustentabilidade como prática de disclosure anuais. O tema também chama a atenção pelo impacto que podem trazer para as organizações em suas práticas empresariais e na forma como são vistas por seus stakeholders.

De acordo com Elkington (1999, 2012), a partir do conceito do Triple Bottom Line - TBL, para que se desenvolva a sustentabilidade, de fato, ela deve envolver as três dimensões da sustentabilidade, econômica, social e ambiental. Segundo ele, ao exercerem suas atividades, as organizações não consomem apenas recursos financeiros, mas também recursos ambientais e sociais. Dessa forma, propôs que o relacionamento das três dimensões da sustentabilidade ocorra de forma 'equilibrada'. Assim, essas dimensões são interdependentes e devem ser consideradas para determinar a sustentabilidade de uma organização.

Muitas organizações acabam adotando práticas de sustentabilidade, não somente por vontade própria, mas também por pressões exercidas por seus parceiros comerciais e pela sociedade. Em decorrência dessa pressão, a busca pela sustentabilidade organizacional tornou-se um dos grandes desafios das empresas, as quais buscam a incorporação da sustentabilidade, em meio à gestão empresarial, na tentativa de conciliar o equilíbrio da sustentabilidade; ao mesmo tempo em que procuram garantir lucro e retorno aos empresários e/ou acionistas, protegem o meio ambiente e melhoram a qualidade de vida das pessoas com quem mantém relações em suas atividades (CARVALHO; STEFANO; MUNCK, 2015). Para Galleli e 
Hourneaux Jr. (2019), se as competências da organização são gerenciadas de forma estratégica, a sustentabilidade será inerente ao seu desenvolvimento.

Entretanto, existem gestores que ainda não percebem importância que a sustentabilidade organizacional tem na atualidade e o impacto que pode trazer para os seus negócios, tanto agora, como no futuro. A sustentabilidade é vista, em alguns casos, como um problema, um assunto na contramão do crescimento, do desenvolvimento e dos objetivos das organizações (ELKINGTON, 2012). Com isso surge o desafio em demonstrar a essas organizações como a adoção das práticas sustentáveis pode ser benéfica, em suas três dimensões, tanto para a organização, quanto para a própria sociedade. As empresas devem voltar seus interesses para a incorporação da sustentabilidade em suas estratégias organizacionais, para que o modelo de gestão inclua, além da dimensão econômica, as dimensões ambientais e sociais (ZYLBERSZTAJN, 2010; GARRIDO, SALTORATO, 2015).

Destacam-se os estudos internacionais de Yong et al. (2019), Roman (2017), George, Siti-Nabiha e Jalaludin (2018) visando a identificação e compreenção da institucionalização da sustentabilidade nas organizações. Dessa forma, visou-se realizer um estudo sobre os níveis e práticas de sustentabilidade e instituicionalização em uma indústria brasileira.

Dessa forma, os recursos devem ser administrados com o intuito de obter melhores resultados, de forma consciente, na conservação dos recursos e no equilíbrio das dimensões da sustentabilidade. Diante disso, surgiu a questão que norteia esta pesquisa: quais os níveis das práticas de sustentabilidade e qual o seu nível de institucionalização em uma empresa? Desta forma, esta pesquisa tem como objetivo principal identificar os níveis das práticas de sustentabilidade e sua institucionalização na empresa pesquisada.

A empresa objeto deste estudo é uma indústria de médio porte (segundo os critérios do SEBRAE, pelo número de colaboradores), mas uma das maiores da região em que está inserida, com potencial de impactar tanto questões ambientais, quanto sociais, além da dimensão econômica local e regional e, por isso, foi escolhida. Esta localizada no interior do Estado do Paraná, atuando no ramo de fabricação de embalagens. Possui mais de 25 anos de atuação no mercado e destaca em sua declaração de valores o compromisso com a responsabilidade social e ambiental.

\section{Referencial Teórico}

\subsection{Sustentabilidade Organizacional}

A preocupação da sociedade com relação às questões sustentáveis e a escassez dos recursos naturais, proveniente do desenvolvimento econômico e das atividades das organizações, vêm crescendo nos últimos anos. Além do impacto no lucro, todo negócio impacta nos ambientes internos e externos, ou seja, desempenho social inadequado ou a falta de políticas de cunho social e ambiental pode trazer sérias implicações para as organizações, acarretando não só prejuízos materiais, como também perdas morais, como consequência da forma pela qual buscam seus resultados, ancorados apenas nos ganhos econômicos, sem preocupação com questões ambientais e sociais. Não há como ignorar essa responsabilidade, pois, 
além das questões éticas, envolve, também, questões econômicas e mercadológicas. (ALIGLERI; ALIGLERI; KRUGLIANSKAS, 2016; ALIGLERI et al., 2009).

Dessa maneira, muitas organizações começam a perceber os benefícios em se tornar uma empresa sustentável pode trazer, tanto às questões econômicas, como também em relação às atitudes nas questões ambientais e sociais, que acabam por refletir a imagem da organização. $E$ para que as organizações possam prosperar no longo prazo, necessitam de estratégias voltadas ao desenvolvimento sustentável em suas três dimensões, as quais devem ser trabalhadas simultaneamente e não de forma isolada. Além da percepção que as empresas veem com relação a benefícios que a sustentabilidade pode trazer, outro fator que contribui para a adoção das práticas de sustentabilidade diz respeito à pressão exercida por seus parceiros para a adoção dessas práticas (ELKINGTON, 2012). Para Yong et al. (2019), a sustentabilidade se tornou o foco principal de muitas organizações devido às mudanças climáticas e às pressões regulatórias e sociais em direção a uma maior responsabilidade ambiental e social.

Da mesma forma, que existe cobrança das empresas, também existe o reconhecimento daquelas instituições que adotam as práticas sustentáveis em suas operações e, por conseguinte, esse reconhecimento transforma-se em benefícios, como, por exemplo, na imagem institucional da organização ou, ainda, na conquista de novos clientes, que tendem a negociar com empresas que adotam práticas sustentáveis (CARVALHO; STEFANO; MUNCK, 2015). Nesse contexto, a sociedade, o governo e os consumidores de forma geral, têm a responsabilidade de cobrar a execução dessas práticas das organizações, no sentido de garantir o fortalecimento e a legitimidade das ações voltadas para a sustentabilidade organizacional (ELKINGTON, 2012).

Para se atingir o patamar sustentável e ser possível usufruir dessas vantagens, as empresas devem buscar o equilíbrio nas dimensões ambientais, econômicas e sociais, tendo como metas ser ambientalmente responsável, socialmente justo e economicamente viável (ELKINGTON, 1999). As organizações podem trabalhar isoladamente cada uma das dimensões, ou até focando em duas delas, mas se esse trabalho acontecer isoladamente, não atenderá ao pressuposto do equilíbrio para alcançar o desenvolvimento sustentável. O equilíbrio das três dimensões é o que faz com que uma organização alcance o almejado desenvolvimento sustentável. A conscientização popular em relação às questões econômicas, ambientais e sociais que podem emergir do cenário empresarial, contribui para que as organizações demonstrem seu compromisso com a sustentabilidade (MACKE; GENARI, 2019).

Para Dyllick e Hockerts (2002) os três pilares possuem diferentes propriedades e, por isso, necessitam de diferentes abordagens. Mas as organizações não devem basear suas decisões apenas em um dos pilares, pois isso pode causar o fracasso de qualquer estratégia em longo prazo. Os autores afirmam, ainda, que para as organizações atingirem a sustentabilidade, devem alavancar seus capitais econômicos, sociais e ambientais, integrando-os de forma que se influenciem mutuamente.

Após a idealização do TBL, surgiram outros trabalhos baseados no estudo de Elkington (1999, 2012), como a pesquisa de Dyllick e Hockerts (2002) na qual destacam critérios determinantes para 0 acontecimento da sustentabilidade organizacional. Outros trabalhos baseado no TBL foram desenvolvido por van 
Marrewijk (2003) e van Marrewijk e Werre (2003), em que os autores apresentam a chamada matriz da sustentabilidade, que contém seis níveis escalonados para o desenvolvimento de sustentabilidade organizacional. (MUNCK, 2013).

Os seis níveis de sustentabilidade organizacional na matriz de sustentabilidade, estão em ordem crescente com relação à complexidade da sustentabilidade, sendo compostos conforme o Quadro 1:

Quadro 1 - Matriz de Sustentabilidade - Níveis de Sustentabilidade

\begin{tabular}{|c|c|c|}
\hline & $\begin{array}{c}\text { Nível de } \\
\text { Sustentabilidade }\end{array}$ & Descrição \\
\hline 1 & $\begin{array}{l}\text { Pré-sustentabilidade } \\
\text { empresarial }\end{array}$ & $\begin{array}{l}\text { Não se observa qualquer ambição para se alcançar a } \mathrm{SO}^{1} \text {. No entanto, } \\
\text { podem existir ações iniciadas por meio de pressões externas, como } \\
\text { legislações e exigências de consumidores. }\end{array}$ \\
\hline 2 & $\begin{array}{l}\text { A sustentabilidade } \\
\text { empresarial em } \\
\text { conformidade com a } \\
\text { legislação }\end{array}$ & $\begin{array}{l}\text { A SO' consiste na provisão do bem estar para sociedade dentro dos } \\
\text { limites previstos por normatizações legais. É estimulada por imposições, } \\
\text { obrigatoriedades e por ser admitida como um comportamento correto. }\end{array}$ \\
\hline 3 & $\begin{array}{l}\text { A sustentabilidade } \\
\text { empresarial } \\
\text { orientada pelo lucro }\end{array}$ & $\begin{array}{l}\text { Caracteriza-se por uma integração entre aspectos sociais, éticos e } \\
\text { ambientais nas operações realizadas pela empresa, desde que, gere } \\
\text { algum retorno financeiro. Só será promovida se der algum retorno } \\
\text { rentável. }\end{array}$ \\
\hline 4 & $\begin{array}{l}\text { A sustentabilidade } \\
\text { empresarial } \\
\text { consciente (focada } \\
\text { na conservação) }\end{array}$ & $\begin{array}{l}\text { Busca equilíbrio nas questões sociais, econômicas e ambientais, com o } \\
\text { mesmo grau de importância. As iniciativas vão além das obrigações } \\
\text { legais e retornos financeiros, ela é estimulada pelo potencial humano, } \\
\text { responsabilidade social e o cuidado com o planeta. }\end{array}$ \\
\hline 5 & $\begin{array}{l}\text { A sustentabilidade } \\
\text { empresarial sinérgica }\end{array}$ & $\begin{array}{l}\text { Busca por soluções funcionais e bem elaboradas que agregue valor nos } \\
\text { escopos econômicos, sociais e ambientais. Sua performance é } \\
\text { evidenciada por índices de desempenhos organizacionais. A SO }{ }^{1} \text { é } \\
\text { estimulada pelo reconhecimento da sustentabilidade como um fenômeno } \\
\text { importante por si só. É compreendida como uma ação inevitável para o } \\
\text { progresso da empresa. }\end{array}$ \\
\hline 6 & $\begin{array}{l}\text { A sustentabilidade } \\
\text { empresarial holística }\end{array}$ & $\begin{array}{l}\text { Está extremamente integrada em cada processo dos aspectos envolvidos } \\
\text { no processo de gestão. É estimulada pelo ato de observar a } \\
\text { sustentabilidade como única alternativa de resposta a crise do meio } \\
\text { ambiente. Em que todos possuem uma responsabilidade universal uns } \\
\text { para com os outros. }\end{array}$ \\
\hline
\end{tabular}

${ }^{1} \mathrm{SO}=$ Sustentabilidade Organizacional

Fonte: van Marrewijk e Werre (2003 apud MUNCK, 2013, p. 36)

O Quadro 1 demonstra a evolução das práticas de sustentabilidade nas organizações, que parte da pré-sustentabilidade, que são as primeiras medidas sustentáveis em uma organização, até o nível em que a sustentabilidade já está incorporada nos processos organizacionais e gerenciais da empresa, tornando-se uma prática institucionalizada. Com a crescente legitimação da sustentabilidade e a possibilidade de contestação social decorrentes de pressões ambientais, as organizações passaram a aderir a regras padronizadas e reconhecidas, com o objetivo de coordenar e fortalecer suas ações e posição no mercado. Pode-se interpretar essa adesão de acordo com Wolffenbüttel (2016), como a 
institucionalização de práticas sustentáveis. Roman (2017), destaca que as práticas sustentáveis estão se tornando cada vez mais estabelecidas na comunidade profissional e evoluindo de uma ideia puramente inovadora para uma questão de fato de pensar e fazer negócios.

A tendência é que as empresas adotem estas práticas em suas atividades operacionais a fim de torná-las legítimas em suas organizações, fazendo com que elas sejam institucionalizadas em suas atividades operacionais, seja por iniciativas próprias ou decorrentes de pressões exercidas pela sociedade e parceiros comerciais, conforme será discutido no próximo tópico que discorre sobre teoria institucional voltada para a institucionalização da sustentabilidade.

\subsection{Teoria Institucional}

A institucionalização está relacionada a crenças e valores que são formalizados ou institucionalizados dentro das organizações (TOLBERT; ZUCKER,1999). Para Garrido e Saltorato (2015), a teoria institucional trouxe uma nova forma de enxergar as organizações, na qual atribuem elementos subjetivos às análises das práticas, ações e posturas organizacionais, ou seja, esse novo enfoque passou a considerar a influência de hábitos inconscientes nas ações humanas e, consequentemente, nas ações organizacionais. A teoria institucional é resultado da convergência de meios teóricos sucedidos da ciência da política, da sociologia e da economia que buscam compreender as instituições, seus padrões de comportamentos, de valores e crenças, nos quais os indivíduos, grupos e organizações encontram-se imersos (MACHADODA-SILVA; GONÇALVES; 1999). Além disso, busca compreender as relações entre os elementos da estrutura organizacional que, ao se relacionarem, mantém o equilíbrio do sistema (MOÇATO-DE-OLIVEIRA; SOLA, 2013).

$\mathrm{Na}$ área dos estudos organizacionais, Crubellate, Grave e Mendes (2004) apresentam a teoria institucional como uma opção à concepção de ação social predominante à certo tempo, principalmente, as decisões devem ser geridas por critérios racionais de escolha. E, que, as instituições devem ser compreendidas como definidoras de uma nossa visão do mundo. Dessa maneira, acabam por se transformar em importantes influenciadores do comportamento social. A perspectiva institucional posiciona o ambiente em torno da organização como elemento fundamental na análise de seu comportamento organizacional. Nessa perspectiva, as organizações respondem aos novos valores institucionalizados na comunidade, que acabam tornando-se modelo a ser seguido como ideal num determinado sistema social, na busca por legitimidade social. (BARBIERI et al., 2010; GARRIDO; SALTORATO, 2015; LIMA et al., 2011).

A legitimidade é fundamental para a busca da institucionalização em qualquer rações, em um modelo a ser seguido pelas pessoas que as compõem. A legitimidade se refere ao grau de aceitação que a organização recebe da sociedade, que procura alinhar suas estruturas e ações aos valores do ambiente e conceitos apresentados como socialmente corretos (MUNCK; GALLELI-DIAS; BORIM-DE-SOUZA, 2008). Inicialmente, o conhecimento é institucionalizado dentro de um grupo que interpreta as afirmações como viáveis e plausíveis para aquela comunidade ou organização. $\mathrm{E}$, posteriormente, com a transmissão do conhecimento para as próximas gerações, 
ocorre à legitimação (BERGER; LUCKMANN, 2008; MACHADO; SOUZA; PARISOTTO, 2014).

$\mathrm{Na}$ busca pela perspectiva institucionalista, as organizações visam conformidade com os procedimentos, costumes e regras institucionalizadas num mesmo ambiente com tendência de tornarem-se mais similares entre si. Essa semelhança é definida como isomorfismo - princípio institucional que faz referência à homogeneidade existente entre as organizações (GARRIDO; SALTORATO, 2015).

Machado da Silva e Vizeu (2007, p. 90) destacam que "tendo em vista as características da sociedade moderna, que valoriza o utilitarismo e o pragmatismo, é de se esperar que a tendência seja de valorizar no campo da teoria administrativa aquilo que funciona". Dessa forma, o que funciona tende a ser um conteúdo a ser seguido. Para que uma prática dentro de uma organização se torne instituída, primeiro deve passar pelo processo de institucionalização, o qual pode ser mensurado em níveis de escala. Durante esse período, as organizações sofrem pressões do processo, conforme o interesse material ou simbólico, que pode dificultar ou facilitar a assimilação das práticas (TOLBERT; ZUCKER, 1999).

O processo de institucionalização, conforme Tolbert e Zucker (1999), é dividido em três fases: a habitualização; a objetificação; e a sedimentação:

- Habitualização - é um processo de pré-institucionalização. O resultado é o desenvolvimento de estruturas, com desenvolvimento de padrões de comportamento para resolução de problemas em questão, uma vez que o processo está em início de formação.

- Objetificação - está em direção a um status mais permanente e disseminado na organização. Já desenvolveu alguns hábitos em certo grau de satisfação, além da crescente adoção com base no consenso. Está um nível acima da habitualização, num processo de semi-institucionalização.

- Sedimentação - ocorre quando envolve a total institucionalização; estando apoiado na continuação, em sua sobrevivência pelas várias gerações de membros da organização, passa a fazer parte da história da organização.

A habitualização consiste no processo de mudança organizacional, em busca de desenvolver hábitos da empresa. A objetificação é o próximo passo rumo à institucionalização, uma vez que alguns princípios já estão sendo incorporados na empresa com certo grau de consenso sobre mudanças, nos processos da empresa, através do desenvolvimento de tais práticas, é um processo mais permanente e disseminado de incorporação das mudanças organizacionais. A sedimentação, o último estágio do processo, nesse nível, a institucionalização é total, ou seja, as práticas já foram incorporadas nas atividades operacionais das organizações e têm caráter de continuidade, inclusive para as futuras gerações (TOLBERT; ZUCKER, 1999). O Quadro 2 ilustra os estágios de institucionalização e suas dimensões. 
Quadro 2 - Estágios de institucionalização e dimensões comparativas

\begin{tabular}{l|c|c|c}
\hline \multicolumn{1}{c|}{$\begin{array}{c}\text { Dimensão } \\
\text { Processos }\end{array}$} & $\begin{array}{c}\text { Estágio pré- } \\
\text { institucional } \\
\text { Habitualização }\end{array}$ & $\begin{array}{c}\text { Estágio semi- } \\
\text { institucional } \\
\text { Objetificação }\end{array}$ & $\begin{array}{c}\text { Estágio e total } \\
\text { institucionaliza-ção } \\
\text { Sedimentação }\end{array}$ \\
\hline $\begin{array}{l}\text { Características dos } \\
\text { adotantes }\end{array}$ & Homogêneos & Heterogêneos & Heterogêneos \\
\hline Ímpeto para difusão & Imitação & Imitativo/normativo & Normativa \\
\hline Atividade de teorização & Nenhuma & Alta & Baixa \\
\hline $\begin{array}{l}\text { Variância na } \\
\text { implementação }\end{array}$ & Alta & Moderada & Baixa \\
\hline $\begin{array}{l}\text { Taxa de fracasso } \\
\text { estrutural }\end{array}$ & Alta & Moderada & Baixa \\
\hline
\end{tabular}

Fonte: Tolbert, Zucker (1999, p. 211).

Atualmente, as organizações tem buscado a legitimação da sustentabilidade, sendo esta consequência de algumas forças que impulsionam as organizações a buscá-la, entre as quais cabe destacar, três delas. A primeira diz respeito ao constante aumento da industrialização e os efeitos causados por ela como: poluição; geração de resíduos; escassez de recursos; entre outras agressões ambientais. O segundo fator consiste na integração da sociedade, sem exceção, que exige das organizações posicionamento transparente e responsivo com relação aos seus colaboradores e à comunidade na qual estão inseridas. A terceira força diz respeito às tecnologias existentes para amenizar o efeito da ação humana no planeta, como desenvolvimento renovável de energia, energia solar, aproveitamento ou reaproveitamento de água, originado das chuvas ou de processos produtivos, entre outras (HART; MILSTEIN, 2003; GARRIDO; SALTORATO, 2015).

Diante dessa nova perspectiva, as organizações passaram a rever o discurso e as atitudes em um conjunto que envolve valores, crenças, entre outros, em busca desse desenvolvimento sustentável, sendo mais flexíveis para adoção de tais práticas a fim de sua legitimação perante os seus colaboradores e diante da sociedade como um todo.

Entender como as estratégias e iniciativas de sustentabilidade passam a ser percebidas como legítimas pelos gestores é um passo fundamental para facilitar sua adoção e aplicação efetiva. O ambiente institucional desempenha um papel crucial no apoio ao alcance das metas de sustentabilidade (GEORGE et al., 2018). Alcançar a institucionalização e legitimação é importante para a adoção das práticas de sustentabilidade, influenciando os atores envolvidos sobre a relevância das práticas e tornando as ações cada vez mais espontâneas no dia a dia da organização.

\section{Procedimentos Metodológicos}

Quanto à utilização dos resultados, trata-se de uma pesquisa aplicada, pois "a pesquisa aplicada é muito mais voltada à tomada de decisões gerenciais imediatas" (COOPER; SCHINDLER, 2011 p. 11). Quanto aos fins, é uma pesquisa descritiva e quanto à natureza, é quantitativa, tendo em vista que foram utilizados métodos estatísticos para traduzir em números as opiniões e informações do público 
pesquisado. A dimensão do tempo é transversal, uma vez que a pesquisa foi aplicada apenas uma única vez na empresa, e que representa uma fotografia de determinado momento no tempo. A coleta de dados ocorreu entre os meses de setembro e outubro nos três turnos de funcionamento da empresa.

No que se refere à abordagem da pesquisa, é quantitativa, tendo em vista que os dados foram coletados, filtrados e tabulados, ou seja, preparados para serem submetidos a técnicas e testes estatísticos (MARTINS; THEÓPHILO, 2007). Os questionários foram compostos por afirmativas mensuradas a partir de uma escala intervalar balanceada do tipo Likert, com 5 pontos (1-Discordo Totalmente; 2- Discordo Parcialmente; 3-Nem Concordo nem Discordo; 4-Concordo Parcialmente; 5-Concordo Totalmente).

Os questionários foram elaborados com base nos níveis de sustentabilidade e sua institucionalização. Com relação ao nível de sustentabilidade o instrumento foi criado adaptando-se as questões propostas e utilizadas nos estudos de Scandelari e Cunha (2013), Kuhl et al. (2016a; 2016b) e Lima (2013), já que estes abordam estratégias e práticas de gestão voltadas para a sustentabilidade das organizações. No que se refere ao processo de institucionalização o instrumento de coleta de dados foi criado a partir do estudo de Lima et al. (2011).

Após a coleta de dados, os mesmos foram tabulados e analisados a partir de métodos estatísticos necessários e suficientes para atingir ao objetivo de pesquisa proposto inicialmente: análise descritiva (média e desvio-padrão); teste de diferenças de médias (Teste t e Análise de Variância - ANOVA); consistência interna dos construtos (Alfa de Cronbach).

A organização contava com 480 colaboradores em outubro de 2016 e, para atingir uma amostra com nível de confiança de 95\% e margem de erro de 5\%, seriam necessários 218 questionários válidos, de acordo com os cálculos de amostragem propostos por Barbetta (2002). A amostra obtida correspondeu a 249 questionários aplicados aos colaboradores, sendo que destes 244 foram considerados válidos e 5 excluídos por estarem com seu preenchimento incompleto.

Todos os questionários foram aplicados de maneira direta aos colaboradores da organização, aproveitando momentos em que existia um número de colaboradores significativo reunido (reuniões e encontros), envolvendo colaboradores de todos os setores e de todos os turnos da empresa, que se dispuseram a responder ao questionário de forma voluntária, caracterizando a amostra como não probabilística e por conveniência.

O questionário é formado por quatro blocos, sendo o primeiro destinado a caracterizar os respondentes, em termos de sexo, faixa etária, escolaridade e tempo de atuação na empresa, o segundo refere-se ao processo de institucionalização em suas três fases (Habitualização, Objetificação, Sedimentação), o terceiro relaciona as práticas sustentáveis da organização em suas três dimensões (econômico, social e ambiental) e o quarto bloco envolve o indivíduo perante as suas atitudes em relação às práticas sustentáveis. 


\section{Resultados da pesquisa}

O primeiro aspecto analisado e apresentado é a caracterização da amostra. Entre os pesquisados, 60,2\% (147) são do sexo masculino e $39,8 \%$ (97) do sexo feminino. É possível observar que existe uma predominância dos respondentes do sexo masculino. Em relação aos 480 colaboradores da empresa, aproximadamente $65 \%$ são do sexo masculino e $35 \%$ do sexo feminino. Dessa forma, observa-se que o percentual de homens e mulheres ficou muito próximo da realidade de organização. Comparando a amostra em relação ao total de colaboradores da empresa, em função do sexo, não se constata diferenças significativas a partir do teste do Qui-Quadrado (Qui-Quadrado $=2,424$; Significância $=0119$ ), o que indica a representatividade da amostra em relação ao sexo.

Com relação à faixa etária, 106 (43\%) colaboradores estão na faixa de 27 a 40 anos, 51 (21\%) estão na faixa de 23 a 26 anos, 44 (18\%) estão na faixa de 18 a 22 anos e $43(17,6 \%)$ na baixa acima dos 40 anos. Portanto, analisando a amostra da faixa etária, percebe-se que cerca de $2 / 3(60,7 \%)$ dos indivíduos são jovens com até 33 anos de idade. Do total de colaboradores da empresa, aproximadamente $19 \%$ tem até 22 anos de idade; em torno de 17\% possuem idade entre 23 e 26 anos, cerca de $22 \%$ com idade variando de 27 a 33 anos, 20\% tem entre 34 e 40 anos de idade e, aproximadamente, $22 \%$ de seus funcionários tem mais de 40 anos. De forma geral, a organização tem $58 \%$ de seus colaboradores composto por jovens de até 33 anos de idade. Verificando a amostra também é representatividade em relação a idade dos colaboradores (Qui-Quadrado = 4,800; Significância =0,308).

Em relação à escolaridade, 44,3\% (108) da amostra possui o ensino médio, $23,8 \%$ (58) não concluíram o ensino fundamental e 16,4\% (40) concluíram apenas o ensino fundamental. Apenas 15,6\% (38) dos pesquisados possuem ensino superior, e destes, 4,5\% (11) possuem algum tipo de especialização, pós-graduação. Quanto a representatividade da amostra considerando a escolaridade, não foi possível efetuar os cálculos porque a empresa não possui dados atualizados da escolaridade de seus colaboradores.

Outra característica levantada se refere ao tempo em que os colaboradores trabalham na empresa. Do total de respondentes, $41 \%$ (100) pesquisados têm menos de um ano na organização; 33,2\% (81) são os colaboradores que têm entre um e cinco anos de tempo na empresa; e 25,8\% (63) são colaboradores com mais de cinco anos, o que demonstra que a organização tem uma rotatividade considerável entre seus colaboradores. No total a empresa tem aproximadamente $47 \%$ de seus colaboradores com até 1 ano de casa, $28 \%$ tem entre 1 e 5 anos de tempo de empresa e $25 \%$ trabalha há mais de cinco anos. Da mesma forma, como nas categorizações de sexo e faixa etária, o tempo de empresa dos respondentes também não apresentou diferenças estatisticamente significantes com relação ao total de colaboradores (QuiQuadrado $=4,298$; Significância $=0,117$ ), o que demonstra a representatividade da amostra também em termos de tempo de atuação na empresa.

Antes de se iniciar as análises propriamente ditas, verificou-se a existência de dados ausentes e dados extremos. Com relação aos primeiros, ocorreram alguns poucos pontos de ausência, mas que não comprometem as análises subsequentes. Com relação aos segundos, aproveitou-se para verificar conjuntamente a normalidade dos dados, já que dados extremos afetam diretamente a normalidade. Para verificação 
da normalidade optou-se pelos parâmetros indicados na literatura (FIELD, 2009; HAIR JR. et al., 2005) de valores entre -1 e +1 para a assimetria e entre -3 e +3 para a curtose. Nos casos em que os valores de assimetria e curtose estivessem fora dos parâmetros, optou-se por realizar a substituição dos valores pela soma da média e dois desvios-padrão, seguindo a sugestão de Field (2009). Em sete variáveis foi necessário este ajuste (Q17; Q19; Q20; Q21; Q22; Q23; e Q24), no entanto, em dois casos (Q21 e Q23) este procedimento não resolveu o problema, sendo então as variáveis excluídas das análises subsequentes.

O segundo bloco do questionário envolve o processo de institucionalização, composto por nove variáveis, sendo três para cada uma das fases e institucionalização (habitualização; objetificação; sedimentação). A análise inicial se baseia na estatística descritiva a partir das médias e desvio padrão. A Tabela 1 apresenta as médias e o desvio padrão para este conjunto.

Tabela 1 - Estatística descritiva do Processo de Institucionalização

\begin{tabular}{llcc}
\hline \multicolumn{1}{c}{ Variáveis } & Média & $\begin{array}{c}\text { Desvio } \\
\text { padrão }\end{array}$ \\
\hline Q1 $\begin{array}{l}\text { A empresa tem setor responsável que dá suporte/apoio às práticas de } \\
\text { sustentabilidade. }\end{array}$ & 3,08 & 1,328 \\
Q2 $\begin{array}{l}\text { A empresa promove palestras, reuniões, sobre Sustentabilidade para os } \\
\text { empregados. }\end{array}$ & 3,05 & 1,381 \\
Q3 $\begin{array}{l}\text { A empresa investe em novas tecnologias para melhorar a qualidade dos } \\
\text { serviços e produtos. }\end{array}$ & 3,70 & 1,315 \\
\hline Q4 $\begin{array}{l}\text { A empresa oferece melhoria aos empregados, como qualidade de vida, } \\
\text { segurança no trabalho. } \\
\text { A empresa trabalha com alguma outra empresa que desenvolve questões }\end{array}$ & 3,60 & 1,319 \\
Q5 $\begin{array}{l}\text { de sustentabilidade, como coleta de lixo reciclável ou economia de água e } \\
\text { energia. }\end{array}$ & 3,66 & 1,296 \\
Q6 A empresa oferece inclusão social: programas de estágio, projeto "treine", & 3,00 & 1,556 \\
\hline inclusão em projetos sociais, como menor aprendiz. & $\begin{array}{l}\text { A empresa é comprometida com o desenvolvimento da sociedade, através } \\
\text { de programas, como educação ambiental, coleta lixo reciclável, entre } \\
\text { outros. }\end{array}$ & 3,33 & 1,381 \\
Q empresa demonstra claramente os resultados obtidos da \\
sustentabilidade (reciclagem, ginastica laboral, projetos de aprendiz). \\
$\begin{array}{l}\text { A empresa acompanha seu relacionamento com a comunidade nas } \\
\text { questões ambientais e sociais (jovem aprendiz, coleta de lixo reciclável), } \\
\text { reavaliando seu trabalho. }\end{array}$ & 2,77 & 1,376 \\
\hline
\end{tabular}

Fonte: Elaborado pelos autores.

Com relação às médias relacionadas ao processo de institucionalização, as variáveis Q3, Q4 e Q5, foram as que obtiveram as maiores médias. Apesar de serem as mais elevadas, todas estão localizadas próximas ao ponto 4 da escala (concordância parcial), indicando uma percepção mais elevada nos aspectos que tangem ao investimento em novas tecnologias para melhoria dos serviços e produtos (Q3 - Habitualização), na melhoria da qualidade de vida dos colaboradores (Q4 Objetificação) e no desenvolvimento de ações voltadas a sustentabilidade (Q5 Objetificação). Por outro lado, médias baixas, como as identificadas nas variáveis Q8 e Q9 (Sedimentação), indicam uma baixa percepção em relação a questões de demonstração e acompanhamento dos resultados com a sustentabilidade, 
especialmente nas questões sociais e ambientais, tendendo ao ponto neutro da escala (nem concordo, nem discordo). Considerando que para que as organizações tenham sucesso na institucionalização de suas práticas, é fundamental que os colaboradores tenham conhecimento das práticas exercidas na organização, assim como os resultados obtidos, percebe-se que na empresa objeto do estudo, existe um longo caminho pela frente.

A Tabela 2 apresenta as médias e o desvio padrão para o aspecto relacionado às práticas da organização, divididas de acordo com as três dimensões da sustentabilidade (social; ambiental; econômica), conforme o Bloco 3 do instrumento de coleta de dados.

Tabela 2 - Estatística descritiva relacionada às Práticas da Organização

\begin{tabular}{llcc}
\hline \multicolumn{1}{c}{ Variáveis } & Média & $\begin{array}{c}\text { Desvio } \\
\text { padrão }\end{array}$ \\
\hline Q10 & $\begin{array}{l}\text { A empresa prioriza oportunidade de trabalho para a comunidade local. } \\
\text { A empresa faz investimentos para melhoria da qualidade de vida da }\end{array}$ & 3,89 & 1,310 \\
Q11 & 2,96 & 1,360 \\
Q12 & $\begin{array}{l}\text { A empresa oferece treinamentos e cursos de capacitação a todos os } \\
\text { empregados. }\end{array}$ & 3,13 & 1,499 \\
Q13 & $\begin{array}{l}\text { A empresa busca sugestões dos empregados para melhorias nos } \\
\text { processos para segurança, saúde e bem estar do trabalhador. }\end{array}$ & 3,03 & 1,483 \\
\hline Q14 & $\begin{array}{l}\text { A empresa busca reduzir o consumo de água e energia no processo } \\
\text { produtivo. }\end{array}$ & 3,44 & 1,318 \\
Q15 & $\begin{array}{l}\text { A empresa desenvolve ações para diminuir quantidade de resíduos (lixo) } \\
\text { gerados no processo produtivo. }\end{array}$ & 3,75 & 1,206 \\
Q16 & $\begin{array}{l}\text { A empresa desenvolve a conscientização ambiental dos empregados. } \\
\text { A empresa adota produtos e embalagens que permitam ser reciclados }\end{array}$ & 3,04 & 1,381 \\
Qpós o uso. & 4,07 & 1,050 \\
\hline Q18 & $\begin{array}{l}\text { A empresa busca práticas para diminuir riscos de perdas referentes a } \\
\text { responsabilidade ambiental, de saúde e segurança. }\end{array}$ & 3,72 & 1,179 \\
Q19 & $\begin{array}{l}\text { A empresa busca práticas para diminuir reclamações e devoluções dos } \\
\text { clientes. }\end{array}$ & 4,32 & 0,920 \\
Q20 & A empresa busca ampliar a participação no mercado (novos clientes). & 4,46 & 0,752 \\
\hline & & & \\
\hline
\end{tabular}

Fonte: Elaborado pelos autores.

As médias mais elevadas estão nas variáveis Q19 e Q20 (dimensão econômica), onde a percepção está um pouco acima do nível da concordância parcial da escala, indicando que os colaboradores percebem de maneira mais acentuada as questões relacionadas a esta dimensão. Por outro lado, as médias mais baixas estão nas variáveis Q11 e Q13 (dimensão social), próximas ao ponto neutro da escala (nem concordo, nem discordo), indicando que a maioria das questões relacionadas a dimensão social não são percebidas de forma tão acentuada quanto a maioria das questões da dimensão econômica. Apenas na variável Q10, da dimensão social, a média ficou próxima ao ponto de concordância parcial da escala, e próxima as médias das variáveis da dimensão econômica. No entanto, neste caso também percebe-se que a prática adotada pela empresa pode estar relacionada a questão econômica, pois ao buscar dar oportunidade de trabalho à comunidade local (neste caso comunidade/bairros próximas a empresa) a mesma estará economizando em transporte e alimentação. Com relação as variáveis da dimensão ambiental, percebese que houve as médias variaram bastante, indicando práticas mais contundentes 
(reciclagem e redução de resíduos) e práticas menos expressivas (conscientização e redução de consumo de água e energia).

Faber, Jorna e Engelen (2005), destacam que, a sustentabilidade é um equilíbrio entre um elemento e seu ambiente de apoio, os quais interagem entre si, sem que haja efeitos prejudiciais entre eles. Dessa forma, as três dimensões da sustentabilidade devem ser trabalhadas com sinergia, para que a organização obtenha resultados satisfatórios em todas as dimensões, o que não se consegue observar nas variáveis elencadas na Tabela 2. Esta percepção inicial ficará mais clara quando forem apresentadas as médias por construto (Tabela 4)

A Tabela 3 apresenta a média e o desvio padrão para as variáveis relacionadas ao compromisso frente a sustentabilidade (Bloco 4 do questionário), divididas em práticas individuais relacionadas a questões ambientais e práticas individuais relacionadas a questões sociais.

Tabela 3 - Estatística descritiva do Compromisso frente à Sustentabilidade

\begin{tabular}{clcc}
\hline \multicolumn{1}{c}{ Variáveis } & Média & $\begin{array}{c}\text { Desvio } \\
\text { padrão }\end{array}$ \\
\hline Q22 & $\begin{array}{l}\text { Você descarta corretamente os resíduos (lixo) em sua empresa. } \\
\text { Você economiza energia em sua empresa, como apagar luzes em salas }\end{array}$ & 4,39 & 0,815 \\
Q24 & $\begin{array}{l}\text { vazias, utilizar ventilação natural ao invés de ar condicionado ou } \\
\text { ventiladores. }\end{array}$ & 0,952 \\
\hline Q25 & $\begin{array}{l}\text { Você participa ou promove alguma ação voltada às questões sociais em } \\
\text { sua empresa (ginastica laboral, palestras educativas). } \\
\text { Você é uma pessoa motivada a praticar ação social na empresa } \\
\text { (ginastica laboral, palestras educativas). }\end{array}$ & 2,67 & 1,590 \\
\hline
\end{tabular}

Fonte: Elaborado pelos autores.

Nesse bloco, buscou-se verificar se as práticas adotadas no dia a dia da organização estão sendo incorporadas as práticas do dia a dia dos colaboradores na organização. Neste sentido, as variáveis relacionadas a questão ambiental apresentaram médias mais elevadas que as variáveis relacionadas as questões sociais, sendo que estas apresentam médias dispares, próximas ao ponto neutro da escala, enquanto que aquelas estão acima do ponto de concordância parcial da escala. Este resultado pode indicar que a adoção de práticas voltadas a questão ambiental são mais fáceis de serem implementadas e institucionalizadas, já que pode ser uma atitude individual, que praticamente não exige interação com outros colaboradores, enquanto que as questões relacionadas a dimensão social exigem a interação, o que para alguns indivíduos pode ser uma restrição (timidez).

Na sequência (Tabela 4) são apresentados os construtos com média, desvio padrão e a verificação da consistência interna de cada um por meio do Alfa de Cronbach. Segundo Hair Jr. et al. (2005) um coeficiente aceitável deve estar acima de 0,60 . 
Tabela 4 - Estatística descritiva dos construtos

\begin{tabular}{lcccc}
\hline & Construtos & Média & $\begin{array}{c}\text { Desvio } \\
\text { padrão }\end{array}$ & Alfa \\
\hline \multirow{2}{*}{ Processo de Institucionalização } & Habitualização & 3,29 & 1,097 & 0,725 \\
& Objetificação & 3,43 & 1,092 & 0,668 \\
& Sedimentação & 2,94 & 1,171 & 0,793 \\
\hline \multirow{3}{*}{ Sustentabilidade Organizacional } & Social & 3,26 & 1,035 & 0,681 \\
& Ambiental & 3,58 & 0,979 & 0,792 \\
& Econômica & 4,17 & 0,776 & 0,722 \\
\hline \multirow{2}{*}{ Práticas Sustentabilidade Indivíduos } & Ind_Ambiental & 4,44 & 0,661 & 0,655 \\
& Ind_Social & 3,03 & 1,364 & 0,694 \\
\hline
\end{tabular}

Fonte: Elaborado pelos autores.

No processo de institucionalização, a média da Habitualização $(3,29)$ indica que a percepção dos colaboradores está muito próxima ao ponto neutro da escala, sugerindo que a institucionalização das práticas ainda está aquém daquilo que a organização espera. Neste mesmo sentido, a percepção média dos colaboradores na Objetificação $(3,43)$ pode estar indicando que, aparentemente, a organização já desenvolveu alguns hábitos, mas ainda sem consenso. Já a sedimentação $(2,94)$, pouco abaixo do ponto neutro da escala, indica que as práticas possivelmente não estão institucionalizadas, pelo menos não ao ponto de serem percebidas de forma mais consistente pelos colaboradores.

Em relação as dimensões da sustentabilidade pode-se inferir que os colaboradores percebem mais as práticas econômicas, seguido das práticas ambientais na organização e sendo a dimensão social a o menos perceptível. Este resultado está de acordo com os obtidos por Moçato-de-Oliveira e Sola (2013, p. 2) que destacam em seu estudo que "a partir de constatações como estas vê-se a valorização de aspectos econômicos e a subvalorização de questões sociais e ambientais, que são igualmente importantes para a concretização da sustentabilidade organizacional." Por outro lado, a conscientização dos indivíduos frente aos problemas ambientais e a questões socioeconômicas, acaba sendo $O$ resultado do desenvolvimento sustentável das organizações (MOÇATO-DE-OLIVEIRA; SOLA, 2013), o que pode indicar que o desenvolvimento não é tão sustentável quanto deveria, já que o 'equilíbrio' entre as dimensões proposto por Elkington (1999) não é visualizado, ou seja, a conscientização dos indivíduos ainda não é equânime.

Nos construtos relacionados à atitude dos colaboradores ocorreu uma diferença significativa entre construto Ind_Ambiental $(4,44)$ e Ind_Social $(3,03)$, corroborando a percepção indicada nas duas dimensões da sustentabilidade, de uma maior 'valorização' das questões ambientais que das questões sociais, corroborando a ideia de que a prática de ações voltadas a dimensão ambiental podem ser de mais fácil incorporação que as práticas voltadas a dimensão social, possivelmente por esta exigir um grau de interação social maior que aquela.

Com vistas a verificar se as médias dos construtos, apresentadas na Tabela 4, não estaria sendo influenciada por questões relacionadas as características dos respondentes, verificou-se a existência, ou não, de diferenças estatisticamente significantes entre as médias em função do sexo, tempo de empresa e escolaridade. 
A Tabela 5 compara as médias dos construtos com relação ao sexo dos indivíduos a partir do Teste t para amostras independentes.

Tabela 5 - Comparativo das médias por Sexo

\begin{tabular}{|c|c|c|c|c|c|}
\hline Construto & Sexo & Média & $\begin{array}{l}\text { Desvio } \\
\text { padrão }\end{array}$ & Teste T & Sig \\
\hline \multirow{2}{*}{ Habitualização } & Masculino & 3,293 & 1,076 & \multirow{2}{*}{$-0,013$} & \multirow{2}{*}{0,990} \\
\hline & Feminino & 3,295 & 1,133 & & \\
\hline \multirow{2}{*}{ Objetificação } & Masculino & 3,390 & 1,099 & \multirow{2}{*}{$-0,636$} & \multirow{2}{*}{0,525} \\
\hline & Feminino & 3,481 & 1,086 & & \\
\hline \multirow{2}{*}{ Sedimentação } & Masculino & 2,932 & 1,147 & \multirow{2}{*}{$-0,186$} & \multirow{2}{*}{0,853} \\
\hline & Feminino & 2,960 & 1,211 & & \\
\hline \multirow{2}{*}{ Social } & Masculino & 3,218 & 0,993 & \multirow{2}{*}{$-0,766$} & \multirow{2}{*}{0,444} \\
\hline & Feminino & 3,322 & 1,099 & & \\
\hline \multirow{2}{*}{ Ambiental } & Masculino & 3,557 & 0,914 & \multirow{2}{*}{$-0,386$} & \multirow{2}{*}{0,700} \\
\hline & Feminino & 3,609 & 1,076 & & \\
\hline \multirow{2}{*}{ Econômica } & Masculino & 4,131 & 0,751 & \multirow{2}{*}{$-0,929$} & \multirow{2}{*}{0,35} \\
\hline & Feminino & 4,225 & 0,812 & & \\
\hline \multirow{2}{*}{ Ind_Ambiental } & Masculino & 4,451 & 0,634 & \multirow{2}{*}{0,376} & \multirow{2}{*}{0,708} \\
\hline & Feminino & 4,419 & 0,705 & & \\
\hline \multirow{2}{*}{ Ind_Social } & Masculino & 3,003 & 1,306 & \multirow{2}{*}{$-0,414$} & \multirow{2}{*}{0,680} \\
\hline & Feminino & 3,077 & 1,452 & & \\
\hline
\end{tabular}

Fonte: Elaborado pelos autores.

Os resultados apontados na Tabela 5 indicam que não existem diferenças significativas nos construtos com relação ao sexo dos indivíduos. Este resultado está de acordo com o resultado encontrado por Portugal (2014), em que as variáveis sobre percepção dos indivíduos não apresentam nível de significância relacionado ao sexo dos indivíduos.

A Tabela 6 compara as médias dos construtos com relação ao tempo de atuação na empresa dos indivíduos a partir da Análise da Variância (ANOVA).

Tabela 6 - Comparativo das médias por Tempo de Empresa

\begin{tabular}{llllll}
\hline \multicolumn{1}{c}{ Construto } & \multicolumn{1}{c}{$\begin{array}{c}\text { Tempo de } \\
\text { Empresa }\end{array}$} & Média & $\begin{array}{c}\text { Desvio } \\
\text { padrão }\end{array}$ & F & Sig. \\
\hline \multirow{3}{*}{ Habitualização } & Até 1 ano & 3,410 & 1,071 & & \\
& De 1 a 5 anos & 3,234 & 1,127 & 0,972 & 0,380 \\
& Acima de 5 anos & 3,187 & 1,098 & & \\
\cline { 2 - 6 } Objetificação & Até 1 ano & 3,578 & 1,029 & & \\
& De 1 a 5 anos & 3,393 & 1,038 & 2,066 & 0,129 \\
& Acima de 5 anos & 3,227 & 1,231 & & \\
\cline { 2 - 6 } Sedimentação & Até 1 ano & 3,080 & 1,162 & & \\
& De 1 a 5 anos & 2,862 & 1,085 & 1,169 & 0,313 \\
& Acima de 5 anos & 2,830 & 1,282 & & \\
\hline
\end{tabular}


Tabela 6 - Comparativo das médias por Tempo de Empresa (continuação)

\begin{tabular}{|c|c|c|c|c|c|}
\hline Construto & $\begin{array}{l}\text { Tempo de } \\
\text { Empresa }\end{array}$ & Média & $\begin{array}{l}\text { Desvio } \\
\text { padrão }\end{array}$ & $\mathbf{F}$ & Sig. \\
\hline & Até 1 ano & 3,439 & 0,873 & & \\
\hline \multirow[t]{3}{*}{ Social } & De 1 a 5 anos & 3,187 & 1,088 & 2,825 & 0,061 \\
\hline & Acima de 5 anos & 3,067 & 1,167 & & \\
\hline & Até 1 ano & 3,673 & 0,851 & & \\
\hline \multirow[t]{3}{*}{ Ambiental } & De 1 a 5 anos & 3,576 & 1,012 & 1,195 & 0,305 \\
\hline & Acima de 5 anos & 3,429 & 1,115 & & \\
\hline & Até 1 ano & 4,272 & 0,762 & & \\
\hline \multirow[t]{3}{*}{ Econômica } & De 1 a 5 anos & 4,118 & 0,766 & 1,599 & 0,204 \\
\hline & Acima de 5 anos & 4,067 & 0,802 & & \\
\hline & Até 1 ano & 4,483 & 0,609 & & \\
\hline \multirow[t]{3}{*}{ Ind_Ambiental } & De 1 a 5 anos & 4,384 & 0,651 & 0,494 & 0,611 \\
\hline & Acima de 5 anos & 4,436 & 0,754 & & \\
\hline & Até 1 ano & 3,045 & 1,329 & & \\
\hline \multirow[t]{2}{*}{ Ind_Social } & De 1 a 5 anos & 2,833 & 1,378 & 1,833 & 0,162 \\
\hline & Acima de 5 anos & 3,269 & 1,381 & & \\
\hline
\end{tabular}

Fonte: Elaborado pelos autores.

Os resultados apresentados na Tabela 6 não indicam a existência de diferenças estatisticamente significativas, ao nível de 0,05. Porém, percebe-se que à medida que aumenta o tempo de empresa dos colaboradores as médias ficam mais baixas. Todos os construtos do processo de institucionalização e das práticas de sustentabilidade apresentam essa característica. Sendo assim é possível inferir que à medida que os colaboradores adquirem mais tempo de empresa, ficam mais criteriosos e exigentes com relação à percepção das práticas exercidas na organização, seja por sua visão mais detalhada, devido sua experiência, ou mesmo por um senso crítico mais acurado. Pinheiro (2008) também encontrou resultados neste sentido, sugerindo que um colaborador com mais tempo de empresa pode retratar melhor a realidade das atividades da organização. Já nas práticas individuais não se percebe esta distinção tão evidente, mas ainda assim as médias dos colaboradores com mais tempo de casa são elevadas.

A Tabela 7 compara as médias dos construtos com relação a escolaridade dos colaboradores, também a partir da ANOVA. 
Tabela 7 - Comparativo das médias por Escolaridade

\begin{tabular}{|c|c|c|c|c|c|}
\hline Construtos & Escolaridade & Média & $\begin{array}{l}\text { Desvio } \\
\text { padrão }\end{array}$ & $\mathbf{F}$ & Sig. \\
\hline & Fundamental Completo & 3,403 & 1,166 & & \\
\hline \multirow[t]{3}{*}{ Habitualização } & Médio & 3,299 & 1,078 & 1,863 & 0,157 \\
\hline & Superior & 3,000 & 0,926 & & \\
\hline & Fundamental Completo & 3,411 & 1,154 & & \\
\hline \multirow[t]{3}{*}{ Objetificação } & Médio & 3,382 & 1,129 & 0,507 & 0,603 \\
\hline & Superior & 3,587 & 0,791 & & \\
\hline & Fundamental Completo & 2,969 & 1,230 & & \\
\hline \multirow[t]{3}{*}{ Sedimentação } & Médio & 2,927 & 1,128 & 0,041 & 0,960 \\
\hline & Superior & 2,921 & 1,161 & & \\
\hline & Fundamental Completo & 3,266 & 1,076 & & \\
\hline \multirow[t]{3}{*}{ Social } & Médio & 3,202 & 1,017 & 0,544 & 0,581 \\
\hline & Superior & 3,405 & 0,992 & & \\
\hline & Fundamental Completo & 3,689 & 0,994 & & \\
\hline \multirow[t]{3}{*}{ Ambiental } & Médio & 3,532 & 0,983 & 1,242 & 0,291 \\
\hline & Superior & 3,421 & 0,922 & & \\
\hline & Fundamental Completo & 4,209 & 0,792 & & \\
\hline \multirow[t]{3}{*}{ Econômica } & Médio & 4,151 & 0,781 & 0,269 & 0,764 \\
\hline & Superior & 4,110 & 0,730 & & \\
\hline & Fundamental Completo & 4,546 & 0,671 & & \\
\hline \multirow[t]{3}{*}{ Ind_Ambiental } & Médio & 4,415 & 0,665 & 3,407 & 0,035 \\
\hline & Superior & 4,225 & 0,581 & & \\
\hline & Fundamental Completo & 2,943 & 1,467 & & \\
\hline \multirow[t]{2}{*}{ Ind_Social } & Médio & 2,916 & 1,314 & 3,883 & 0,022 \\
\hline & Superior & 3,592 & 1,095 & & \\
\hline
\end{tabular}

Fonte: Elaborado pelos autores.

Com relação à escolaridade dos colaboradores, os construtos do processo de institucionalização e das práticas da organização não apresentam diferenças estatisticamente significativas, porém, os construtos voltados para os indivíduos apresentaram diferenças significativas, tanto nas questões ambientais, como nas questões sociais. Estas questões, dizem respeito, as atitudes dos indivíduos frente às questões ambientais e sociais. Em relação as questões ambientais pode-se inferir que colaboradores que possuem até o ensino fundamental, estariam mais propensos a executar tarefas relacionadas à manutenção dessas questões, como: descartar corretamente lixo, economizar energia. Contudo, nas questões sociais, os colaboradores com ensino superior tenderiam a demonstrar maior motivação e participação em atividades como: ginástica laboral e palestras educativas. Os dois construtos estão ligados a questões de valores, crenças e culturas pessoais, porém, as práticas na organização podem contribuir para mudança de cultura das pessoas, o que representaria a legitimação de tais práticas. Entende-se que o compartilhamento de informações e aprendizagem contribui para o alcance da sustentabilidade, e que, essa conscientização, pode contribuir, para mudanças de comportamento (GARRIDO, SALTORATO, 2015). 


\section{Considerações Finais}

A sustentabilidade está cada vez mais presente nas organizações, em partes fruto de pressões exercidas tanto pela sociedade como por outras organizações (ELKINGTON, 2012; MUNCK, 2013; WOLFFENBÜTTEL, 2016). Nesse sentido, este estudo procurou identificar os níveis das práticas de sustentabilidade e sua institucionalização em uma empresa de embalagens. Foi observado na organização que os aspectos econômicos são mais visíveis pelos colaboradores, do que os aspectos ambientais e sociais. Dessa maneira, pode-se inferir que a busca de resultados econômicos é vista por seus colaboradores como mais relevante, e posteriormente são observadas as questões ambientais e sociais.

A segunda questão perceptível pelos colaboradores diz respeito às questões ambientais. Nessa questão, a organização possui algumas atividades voltadas para a preocupação com dimensão ambiental, o que explica, em parte, a percepção dos colaboradores. A recicladora existente na empresa é um ponto relevante, pois além de reaproveitar resíduos da produção que iriam para o lixo, também colabora com a economia de recursos, uma vez que, reciclados esses rejeitos voltam para o processo produtivo. A dimensão social é a menos perceptível, nessa dimensão pode-se inferir que uma das prováveis causas da baixa percepção seja a falta de divulgação por parte da empresa. As questões sociais são voltadas basicamente de forma interna na organização de maneira a atender os seus colaboradores. Para aperfeiçoar essa dimensão, a organização poderia adotar uma política de divulgação de atividades executadas, como o projeto jovem aprendiz, já adotado na instituição.

Entende-se que a organização está no início do processo de implementação de práticas de sustentabilidade, não possuindo um setor específico para questões sustentáveis, sendo que as práticas existentes na organização são tratadas de forma isolada. Portanto, pode-se inferir que a organização está num processo de présustentabilidade. Isso não significa que a empresa não tenha questões ou práticas relacionadas a sustentabilidade, mas que essas práticas ainda são incipientes e tratando as dimensões de forma não equânime. Como sugestão, a organização pode explicar a seus colaboradores a importância da sustentabilidade através de seus conceitos e da aplicação prática na organização.

Com relação ao processo de institucionalização, os colaboradores têm uma percepção mais forte nas fases de Habitualização e Objetificação, que são as fases iniciais no processo em busca de legitimação de suas práticas, mas ainda de forma bastante incipiente, pois as médias estão muito próximas ao ponto neutro da escala. Já na fase de Sedimentação, onde ocorre à institucionalização total de suas práticas, o resultado obtido foi mais baixo. Ou seja, pode-se entender que os colaboradores não percebem essas características sustentáveis na organização como uma prática que se pretende institucionalizar. Há baixo grau de percepção por parte dos colaboradores em relação as práticas existentes na empresa, como, por exemplo, a ginástica laboral, disponível para todos os colaboradores, mas que muitos ainda não usufruem deste benefício. Ou seja, o processo não está legitimado, provavelmente por esse motivo muitos não a fazem. Como sugestão, a organização deve buscar mecanismos que efetivamente façam que as suas práticas sejam institucionalizadas, inicialmente buscando a habitualização e a objetivação, para que na sequencia natural as mesmas sejam sedimentadas. 
Pelos resultados, pode-se inferir que a organização encontra-se no processo de habitualização ou estágio pré-institucional. A empresa busca criar novos arranjos estruturais em resposta a incertezas do mercado externo ou a problemas organizacionais específicos. Nessa fase, as organizações que estão vivenciando problemas semelhantes podem adotar soluções satisfatórias desenvolvidas por outras organizações, conduzindo a invenção simultânea (TOLBERT; ZUCKER, 1999). Apesar da existência de algumas práticas, é necessário o aprimoramento e a interrelação entre tais práticas.

Por fim, pode-se concluir que os níveis de sustentabilidade, a partir das três dimensões, não estão equilibrados, pendendo para a dimensão econômica, em detrimento da dimensão social. No entanto, este resultado já era esperado pois, segundo Elkington (2012), as organizações, embutidas em um sistema econômico capitalista, pautam a sustentabilidade inicialmente buscando harmonizar a dimensão econômica às questões ambientais e sociais. Em relação a institucionalização das práticas de sustentabilidade, pode-se concluir que a organização ainda está no início do processo (pré-institucionalização). Destaca-se que as características dos respondentes não interferem nos resultados, pois não se identificou diferenças estatisticamente significantes nas médias em função destas, exceto no caso das práticas individuais em relação ao grau de escolaridade.

O estudo apresenta limitações, tendo sido realizado em apenas uma unidade organizacional, através de amostragem não probabilística e por conveniência, o que significa que os resultados não representam o todo da organização e, tampouco, podem ser extrapolados para outras organizações, mesmo que de mesmo porte ou ramo de atividade.

Com relação a pesquisas futuras, esta pesquisa pode ser aplicada em outras organizações para identificar a institucionalização das práticas sustentáveis, bem como na própria organização, futuramente, para fins de comparação com a situação atual e futura da organização, relacionada às práticas sustentáveis e à institucionalização dessas práticas.

\section{Referências}

ALIGLERI, L.; ALIGLERI, L.A.; KRUGLIANSKAS, I. Cradle to Cradle: uma Análise dos Produtos Certificados para Limpeza Geral e Lavagem de Roupa. Revista Eletrônica de Gestão Organizacional, v. 14, n. Ed. Especial, p. 88-96, 2016.

ALIGLERI, L.; ALIGLERI, L.A.; KRUGLIANSKAS, I. Gestão Socioambiental: responsabilidade e sustentabilidade do negócio. São Paulo, Atlas, 2009.

BARBETTA, P.A. Estatística aplicada às ciências sociais. 5. Ed. Florianópolis: UFSC, 2002.

BARBIERI, J.C.; SIMANTOB, M.A. (Org.). Organizações Inovadoras sustentáveis. São Paulo: Atlas, 2007. 
BARBIERI, J.C.; VASCONCELOS, I.F.G.; ANDREASSI, T.; VASCONCELOS, F.C. Inovação e Sustentabilidade: novos modelos e proposições. Revista de Administração de Empresas - RAE, São Paulo, v. 50, n. 2, p. 146 -154. abr./jun. 2010.

BARKEMEYER, R.; PREUSS, L.; TSANG, S. What Happened to the 'Development' in Sustainable Development? Business Guidelines Two Decades After Brundtland. Sustainable Development, v. 32, p. 15-32.2014.

BERGER, P.; LUCKMANN, T. A construção social da realidade: tratado de sociologia do conhecimento. Petrópolis: Vozes, 2008.

CARVALHO, A.C.V.; STEFANO, S.R.; MUNCK, L. Competências voltadas à sustentabilidade organizacional: um estudo de caso em uma indústria exportadora. Gestão \& Regionalidade, v. 31, p. 33-48, 2015.

COOPER D.R.; SCHINDLER, P.S. Métodos de pesquisa em Administração. 10. ed. Porto Alegre: Bookman, 2011.

CRUBELLATE, J.M.; GRAVE, P.S.; MENDES, A.A. A questão institucional e suas implicações para o pensamento estratégico. Revista de Administração Contemporânea - RAC, v. 8, n. 3, p. 37-60, 2004. Edição especial.

DYLLICK, T.; HOCKERTS, K. Beyond the business case for corporate sustainability. Business Strategy and the Environment, v.11, n. 1, p.130-141, 2002.

ELKINGTON, J. Cannibals with forks: the triple bottom line of 21 st century business. Oxford: Capstone Publishing Limited, 1999.

ELKINGTON, J. Canibais com garfo e faca. São Paulo: Makron, 2012.

FABER, N.; JORNA, R.; ENGELEN, J.V. The sustainability of "sustainability" - a study into the conceptual foundations of the notion of "sustainability". Journal of Environmental Assessment Policy and Management, v. 7, n.1, p. 1-33, 2005.

FIELD, A. Descobrindo a Estatística usando o SPSS. Trad. Lori Viali. 2 ed. Porto Alegre: Artmed, 2009.

GALLELI, B.; HOURNEAUX JR., F. Human competences for sustainable strategic management: evidence from Brazil, Benchmarking: An International Journal, 2019. https://doi.org/10.1108/BIJ-07-2017-0209

GARRIDO, G.; SALTORATO, P. Isomorfismo, eficiência simbólica e legitimidade social na institucionalização da sustentabilidade socioambiental nas organizações contemporâneas. Perspectivas em Gestão \& Conhecimento, João Pessoa, v. 5, n. 2, p. 69-82, jul./dez. 2015.

GEORGE, R.A.; SITI-NABIHA, A.K.; JALALUDIN, D. Sustainability institutionalisation: A mechanistic approach to control change. Journal of Cleaner Production, v. 205, p. 36-48, 2018. 
HAIR JR., J.F.; BABIN, B.; MONEY, A.H.; SAMUEL, P.; Fundamentos de métodos de pesquisa em administração. Trad. Lene Belon Ribeiro. Porto Alegre: Bookman, 2005.

HART, S.L.; MILSTEIN, M.B. Creating Sustainable Value. Academy of Management Executive, v. 17, n. 2, p. 56-69, 2003.

JABBOUR, C.J.C.; SANTOS, F.C.A. Desenvolvimento de produtos sustentáveis: o papel da gestão de pessoas. Revista de Administração Pública - RAP. Rio de Janeiro, v. 41, n. 2, p. 283-307, mar./abr. 2007.

KAYAGA, S.; MUGABI, J.; KINGDOM, W. Evaluating the institutional sustainability of an urban water utility: A conceptual framework and research directions. Utilities Policy, v. 27, p. 15-27, 2013.

KUHL, M.R.; CUNHA, J.C.; MAÇANEIRO, M.B.; CUNHA, S.K. Collaboration for Innovation and Sustainable Performance: Evidence of Relationship in ElectroElectronic Industry. Brazilian Business Review - BBR, v.13, p.1 - 25, 2016a.

KUHL, M.R.; CUNHA, J.C.; MAÇANEIRO, M.B.; CUNHA, S.K. Relationship between innovation and sustainable performance. International Journal of Innovation Management. p. 1650047 - 1650047-17, 2016b.

LEFF, E. Racionalidade Ambiental: a reapropriação social da natureza. Rio de Janeiro: Civilização Brasileira, 2006.

LIMA, T.C.A.; CABRAL, A.C.A.; PESSOA, M.N.M.; SANTOS, S. M. A institucional das práticas de responsabilidade social: um estudo da companhia de água e esgoto do Ceará. Revista Contemporânea de Economia e Gestão, v. 9, n.1, p. 79-95, 2011.

LIMA, L.F. Estratégias e práticas de gestão, orientadas à sustentabilidade, apropriadas pelas cooperativas agropecuárias do sul do Brasil. Tese de Doutorado. Universidade Federal do Paraná, Curitiba, 2013.

MACHADO-DA-SILVA, C.L.; GONÇALVES, S.A. Nota técnica: a Teoria Institucional.In: CLEGG, S.R.; HARDY, C.; NORD, W.R. Handbook de estudos organizacionais. Vol. 1. São Paulo. Atlas, 1999.

MACHADO-DA-SILVA, C.L.; VIZEU, F. Análise institucional de práticas formais de estratégia. Revista de Administração de Empresas - ERA, v. 47, n.4, p. 89-100, Out-Dez. 2007.

MACHADO JR., C.; SOUZA, M.T.S.; PARISOTO, I.R.S.; Institucionalização do Conhecimento em Sustentabilidade Ambiental pelos Programas de Pós-gradução Stricto Sensu em Administração. Revista de Administração Contemporânea - RAC, Rio de Janeiro, v. 18, n. 6, p. 854-873, Nov./Dez. 2014.

MACKE, J.; GENARI, D. Systematic literature review on sustainable human resource management- Journal of cleaner production, v. 208, p. 806-815, 2019.

MARTINS, G. de A.; THEÓPHILO, C.R. Metodologia da investigação científica para ciências sociais aplicadas. São Paulo: Atlas, 2007. 
MOÇATO-DE-OLIVEIRA, E.W.; SOLA, D.D.L. A Institucionalização do Pilar Econômico da Sustentabilidade e a Subvalorização dos Pilares Social e Ambiental. Revista Capital Científico Eletrônica - RCCe, v. 11, n.3, p. 43-57, 2013.

MUNCK, L. Gestão da sustentabilidade nas organizações: um novo agir frente à lógica das competências. São Paulo: Cengage Learning, 2013.

MUNCK, L.; GALLELI-DIAS, B.; BORIM-DE-SOUZA, R. Sustentabilidade organizacional: uma análise a partir da institucionalização de práticas ecoeficientes. Revista Brasileira de Estratégia - REBRAE, v. 1, n.3, p. 285-295, 2008.

MUNCK, L.; SOUZA, R. B. A relevância do ser humano no contexto de institucionalização e legitimação do paradigma da sustentabilidade. Revista de Gestão USP - REGE, v. 16, n. 3, p. 1-14, 2009.

PINHEIRO, P.F. Implantação da responsabilidade social empresarial na gestão de fornecedores da construção civil - análise do programa TEAR. Dissertação (mestrado). Escola Politécnica da Universidade de São Paulo. 2008.

PORTUGAL, N.S. Gestão e sustentabilidade: um estudo sobre as ações e percepções dos microempreendedores individuais da microrregião de Varginha - MG. Dissertação (mestrado). Universidade Federal de Lavras - UFLA. 2014.

ROMAN, A.V. Institutionalizing sustainability: A structural equation model of sustainable procurement in US public agencies. Journal of Cleaner Production, v.143, p.1048-1059, 2017.

SCANDELARI, V.R.N.; CUNHA, J.C. Ambidestralidade e desempenho socioambiental de empresas do setor eletroeletrônico. Revista de Administração de Empresas RAE, 2013, v. 53 n. 2, p, 183-198

TOLBERT, P.S.; ZUCKER, L.G. A Institucionalização da Teoria Institucional. In Handbook de Estudos Organizacionais. São Paulo, Atlas, 1999.

VAN MARREWIJK, M.; WEERE, M. Multiple levels of corporate sustainability. Journal of Business Ethics, v. 44, n. 2-3, pag.107-119, 2003.

VAN MARREWIJK, M. Concepts and definitions of CSR and corporate sustainability: between agency and communion. Journal of Business Ethics, v. 44, n. 1, p. 95-105, 2003.

WOLFFENBÜTTEL, R.F. Sustentabilidade e ação socioeconômica: a rede produtiva do plástico verde. Ciências Sociais Unisinos, v. 52, n. 3, p. 362-372, 2016.

YONG, J.Y.; YUSLIZA, M.Y.; RAMAYAH, T.; JABBOUR, C.J.C.; SEHNEM, S.; MANI, V. Pathways towards sustainability in manufacturing organizations: Empirical evidence on the role of green human resource management. Business Strategy and the Environment, p. 1-17, 2019.

ZYLBERSZTAJN, D. Sustentabilidade e geração de valor: a transição para o século XXI. Rio de Jane: Elsevier, 2010. 